\title{
A Cohesive Zone Model Taking Account Of The Effect Of Through- Thickness Compression
}

DOI:

10.1016/j.compositesa.2017.03.015

\section{Document Version}

Accepted author manuscript

Link to publication record in Manchester Research Explorer

\section{Citation for published version (APA):}

Zou, Z., \& Lee, H. (2017). A Cohesive Zone Model Taking Account Of The Effect Of Through- Thickness Compression. Composites Part A: Applied Science and Manufacturing, 98, 90-98.

https://doi.org/10.1016/j.compositesa.2017.03.015

\section{Published in:}

Composites Part A: Applied Science and Manufacturing

\section{Citing this paper}

Please note that where the full-text provided on Manchester Research Explorer is the Author Accepted Manuscript or Proof version this may differ from the final Published version. If citing, it is advised that you check and use the publisher's definitive version.

\section{General rights}

Copyright and moral rights for the publications made accessible in the Research Explorer are retained by the authors and/or other copyright owners and it is a condition of accessing publications that users recognise and abide by the legal requirements associated with these rights.

\section{Takedown policy}

If you believe that this document breaches copyright please refer to the University of Manchester's Takedown Procedures [http://man.ac.uk/04Y6Bo] or contact uml.scholarlycommunications@manchester.ac.uk providing relevant details, so we can investigate your claim.

\section{OPEN ACCESS}




\title{
A Cohesive Zone Model Taking Account Of The Effect Of Through- Thickness Compression
}

\author{
Zhenmin Zou*, Hao Lee \\ School of Mechanical, Aerospace and Civil Engineering, The University of Manchester, \\ Manchester M13 9PL, UK
}

Experiments in the literature show that through-thickness compressive stress significantly enhances interfacial fracture resistance. Most existing cohesive zone and interface element models which consider the enhancement only introduce friction in the model. In this paper, a new method is proposed to include both friction and enhanced interfacial shear strength in a cohesive zone model. Contact and friction at micro/macro crack closure is added to the cohesive constitutive law. A traction-based failure function and an energy-based failure function are employed and combined to construct a damage surface. An enhancement of interfacial shear strength due to through-thickness compressive stress is introduced into the traction-based function which governs the damage initiation, while the energy-based function controls the damage growth. The damage surface shrinks in the traction space as damage develops and leads to a softening cohesive constitutive law. The model is employed to simulate shear failure of symmetric double notch specimens and delamination failure in specimens with cut- and dropped-plies. Numerical predictions are in good agreement with available experimental data in the literature. Parametric studies show that both the friction at crack closure and enhancement of the interfacial shear strength play an important role in enhancing fracture resistance.

KEY WORDS: Cohesive zone model; interface element; friction; damage; through-thickness compression.

* Corresponding author. Email: z.zou@manchester.ac.uk 


\section{Introduction}

Cohesive zone model was first originated in the 1960s by Dugdale [1] and Barenblatt [2]. Various versions of cohesive zone and interface element models have been proposed since then and have been widely used to simulate damage initiation and propagation in structures, such as debonding in composite materials [3, 4], delamination in laminated composites [5, 6] and adhesive bonding failure [7, 8]. Reviews on the cohesive interface models were presented by Yang and Cox [9] and Raous [10].

Damage initiation and propagation in structures are usually in mixed mode. When the interface is under compression in through-thickness direction, the effect of the throughthickness stress is ignored in most of the existing cohesive interface models. However, evidence from experiments has shown that through-thickness compression can increase the resistance to mode II failure, i.e., enhancing the mode II fracture energy [11] and significant gains in improving the interlaminar shear strength $[12,13]$. Excluding the effect of throughthickness compression will underestimate the failure load or over predict the extent of interfacial damage in structures.

Attempts have been made to consider the effect of through thickness compression in open literature. Internal material friction has been used to explain the increased shear strength under compression and several researchers $[14,15]$ have modified the interlaminar shear strength by linking it to an internal friction factor. Cui et al. [11] employed variable fracture toughness based on compressive stress. The average compressive through-thickness stress over the compressive zone at the delamination tip was first determined and the Mode II fracture energy was expressed as a linear function of the average though-thickness compressive stress. This approach is not practical for progressive delamination/crack growth analysis, since the average through-thickness compressive stress is a solution variable itself.

Friction in the cracked area under through-thickness compression is inevitable and has been

proved to have a major role in increasing delamination stress or fracture toughness in composite laminates. Li and Wisnom [16] modelled the friction on the delaminated interface in composite specimens with cut and dropped plies and simulated the delamination stress. It was found that including friction with a coefficient of 1.0 increased the failure stress by $12 \%$ for cut-ply specimen and $27 \%$ for dropped ply case. Numerical and analytical studies have been conducted to investigate the effect of frictional force on the accuracy of the measured 
mode II delamination resistance in end-notched flexure (ENF) and 4-point ENF [17]. It has been shown that the frictional force between the surfaces of the artificial starting defect can slow down the crack propagation significantly, resulting in higher delamination resistance.

Conventional cohesive zone and interface element models have been modified to combine cohesive damage and frictional contact phenomenon. The simplest approach was to introduce frictional stress into the model once complete decohesion has been achieved $[3,18,19]$. Some researchers $[20,21,22]$ activated frictional stress in the cohesive model as soon as decohesion starts. Complete coupling of damaging and friction in cohesive zone model has also been developed to allow a smooth transition from pure cohesive damaging behaviour to purely frictional one. Alfano and Sacco [23] combined interface damage and friction in a cohesive zone model using a simplified micromechanics method. A representative elementary area of the interface was created and decomposed into an undamaged part and a completely damaged part. Friction is assumed to occur only on the damaged part and its behaviour is governed by the Coulomb friction law. Alfano and his co-workers have further extended the model to deal with mixed mode fracture with different mode I and mode II fracture energies [24] and to account for dilation and asperity degradation [25]. Similar coupling model was proposed by Parrinello et al. [26] in a thermodynamically consistent framework.

Only a few researchers considered the interfacial shear strength enhancement in the cohesive zone/interface element model. Li et al. [27] proposed an interfacial failure model for interface element to take into account the effect of compressive through-thickness stress. An enhancement parameter analogous to an internal friction coefficient was employed to relate the through-thickness compressive stress to the increase in interfacial shear strength and mode II fracture energy. There is no direct friction involved in the model and therefore postdamage friction is not included. Application of the model to delamination failure in composite specimens shows that high internal friction coefficients are needed to enable the model to achieve good agreement between predictions and experimental results. Vandellos et al. [28] developed a cohesive model which takes into consideration the reinforcing influence of the through-thickness compression on the interfacial shear strength for damage onset criterion.

There is little work in the literature which attempts to include both friction and enhancement of interfacial shear strength in cohesive/interface element model, apart from that in [29]. Guiamatsia and Nguyen [29] assumed that the enhanced shear strength is simply the sum of 
the initial shear strength and the critical frictional shear stress. They applied their model to delamination in a composite laminate subjected to impact loading, and acknowledged that it was necessary to use a high coefficient of friction 0.8 in order to closely match the predictions with the experimental results, although a value of 0.5 is roughly within the range of the measurements [30]. The enhanced shear strength governs the damage initiation and there is no friction when damage initiates. This use of frictional stress to enhance the shear strength in [29] may be inappropriate. Therefore, there is still a need to develop a robust cohesive zone/interface element model which can handle both enhanced interfacial shear strength and friction at crack closure to fully take account of the effect of through-thickness compression.

In this paper, a two-dimensional cohesive zone model is proposed, a modification of the damage model developed by Zou et al. [31] to take into account the effect of compressive through thickness stress. Both of the friction and enhancement of interfacial shear strength are included, but in a different and simpler way than that in [29]. Contact and friction at crack closure are added to the cohesive constitutive law. Compressive through thickness stress is introduced into a traction-based damage initiation criterion to enhance the interfacial shear strength so that higher shear traction is required to initiate damage on the interface. A damage surface is also constructed to derive the damage evolution law and to establish a softening cohesive constitutive law. Numerical simulations have been carried out to assess delamination failure in composite laminated specimens. Effort has been made to use realistic coefficients of friction measured from experiments available in literature. Predictions are in good agreement with experimental results in the literature [11, 13]. It was demonstrated that both the friction at crack closure surface and the enhancement of the interfacial shear strength play an important role in enhancing fracture resistance.

\section{Cohesive Zone Model}

For the conventional cohesive zone and interface element models, the relationship between the tractions $\tilde{\tau}_{i}$ and separations $\delta_{i}(i=1,2)$ of the interface can be expressed as

$$
\begin{array}{ll}
\tilde{\tau}_{1}=k_{1} \delta_{1} & \text { if } \delta_{1}<0 \\
\widetilde{\tau}_{1}=(1-\omega) k_{1} \delta_{1} & \text { if } \delta_{1}>0 \\
\tilde{\tau}_{2}=(1-\omega) k_{2} \delta_{2} &
\end{array}
$$

where $k_{i}$ is constraint or penalty stiffness of the interface. $\omega$ is a damage parameter of the 
interface, chosen to describe the extent of damage. $\omega=0$ represents the undamaged state and $\omega=1$ indicates a fully damaged/cracked state. A local co-ordinate system is defined such that subscript 1 indicates the normal through-thickness direction and subscript 2 is the shear direction in the interface, corresponding to the conventional definitions of modes of fracture.

When the interface is under through-thickness compression $\left(\delta_{1}<0\right)$, damage has no effect on the compressive stiffness of the interface. However, contact between the surfaces of the damaged interface (micro- and macro-cracks) leads to interfacial friction. Alfano and Sacco [23] introduced a representative interface area and partitioned it into an 'undamaged' part and a 'damaged' part. For a unit representative interface area, the 'undamaged' part accounts for an area of $(1-\omega)$ and the 'damaged' part is of an area of $\omega$. A unilateral contact with friction takes place only in the 'damaged' part. To consider the possible contact and friction, the conventional interface model in Eq. (1) is modified and a new set of symbols $\tau_{i}$ are used to denote tractions with friction on the surfaces of the interface. They are expressed as follows.

When $\delta_{1}>0$

$$
\begin{gathered}
\tau_{1}=\tilde{\tau}_{1}=(1-\omega) k_{1} \delta_{1} \\
\tau_{2}=\tilde{\tau}_{2}=(1-\omega) k_{2} \delta_{2}
\end{gathered}
$$

When $\delta_{1}<0$

$$
\begin{aligned}
& \tau_{1}=\tilde{\tau}_{1}=k_{1} \delta_{1} \\
& \tau_{2}=\tilde{\tau}_{2}+\omega \tau_{f}=(1-\omega) k_{2} \delta_{2}+\omega \tau_{f}
\end{aligned}
$$

where $\tau_{f}$ is the frictional stress on the damaged part of the interface. It is found using the Coulomb friction law $[23,32]$

$$
\begin{array}{ll}
\tau_{f}=k_{2}\left(\delta_{2}-\delta_{s}\right) & \text { if } k_{2}\left|\delta_{2}-\delta_{s}\right|+\mu \tau_{1}<0 \\
\tau_{f}=-\mu \tau_{1} \frac{\delta_{2}-\delta_{s}}{\left|\delta_{2}-\delta_{s}\right|} & \text { if } k_{2}\left|\delta_{2}-\delta_{s}\right|+\mu \tau_{1} \geq 0
\end{array}
$$

where $\delta_{s}$ is a frictional sliding displacement and $\mu$ is the coefficient of friction.

The shear traction/stress acting on the interface comes from two sources, i.e. the cohesive shear stress $\tilde{\tau}_{2}$ from the cohesion and the frictional stress $\omega \tau_{f}$. The modification made to the 
interfacial cohesive constitutive law above takes into account the possible contact and friction between the surfaces of damaging and fully damaged interface.

The cohesive interface model has two sets of primary parameters, interfacial strengths and fracture energies. The former controls the initiation of damage on the interface and the latter governs the propagation of the damage. Experiments $[12,13]$ have demonstrated that the through-thickness compressive stress has a significant effect on the enhancement of interfacial shear strength. Criteria have been proposed for interlaminar shear failure of composite laminates with through-thickness compression $[15,33,34]$. The following stressbased failure function developed by $\mathrm{Li}$ et al. [27] is employed in the present work for interfacial damage initiation:

$$
\begin{array}{ll}
f_{s}=\left(\frac{\tilde{\tau}_{1}}{\tau_{1 c}}\right)^{2}+\left(\frac{\tilde{\tau}_{2}}{\tau_{2 c}}\right)^{2} & \text { when } \tilde{\tau}_{1}>0 \\
f_{s}=\left(\frac{\tilde{\tau}_{2}}{\tau_{2 c}-\eta \tilde{\tau}_{1}}\right)^{2} & \text { when } \tilde{\tau}_{1}<0
\end{array}
$$

where $\tau_{1 c}$ and $\tau_{2 c}$ are the tensile and shear strength of the interface and $\eta$ is an enhancement factor for the interfacial shear strength due to through thickness compressive stress. Only the cohesive stresses are included in the above failure function $f_{s}$. Friction contributes to the failure of the interface indirectly. Frictional stress is included in the shear stress in equation (3) to resist sliding separation of the interface and affects the magnitude of the cohesive shear stress via structural response.

During the process of damage growth, energy dissipates due to decohesion at the interface and the possible friction. The damage induced energy dissipation rates for cohesive failure are defined as

$$
G_{i}=\int_{\delta_{i 0}}^{\delta_{i}} \widetilde{\tau}_{i} d \delta_{i} \quad(i=1,2)
$$

where $\delta_{i 0}$ are separations at damage initiation when $f_{s}=1$ is first met. $G_{i}(i=1,2)$ correspond to mode I and mode II energy dissipation respectively (and the arabic numbers replacing their roman counterparts without confusion).

A fracture-mechanics-based failure function for interfacial damage propagation can be 
expressed as

$$
f_{g}=\left(\frac{G_{I}}{G_{I c}}\right)^{\alpha}+\left(\frac{G_{I I}}{G_{I I c}}\right)^{\beta}
$$

where $G_{i C}(i=\mathrm{I}, \mathrm{II})$ are the individual fracture energies. $\alpha=\beta=1$ and $\alpha=\beta=2$ are most frequently chosen in the literature, which correspond to linear and quadratic failure criteria, respectively.

The damage initiation and evolution are unified by introducing a combined form of the traction-based failure criterion and fracture-mechanics-based failure criterion. A damage surface in the $\tilde{\tau}_{i}$ and $G_{i}$ space is constructed [31]

$$
F=f_{s}+f_{g}-1=0
$$

Before damage initiation, the interface is intact and has a large initial stiffness. Interfacial separation $\delta_{i}$ is very small, and $G_{i}$ and $f_{g}$ are equal to zero. The damage surface is indeed a stress-based criterion for damage initiation. As the damage initiates at $f_{s}=1$ and develops subsequently, the stiffness of the interface $(1-\omega) k_{i}$ degrades and $f_{g}$ increases rapidly. This leads to a shrinking damage surface in the cohesive traction space and consequently lower cohesive tractions are required for further damage as expected. A softening interfacial cohesive constitutive relationship is therefore established. When the fracture mechanics failure function $f_{g}$ reaches unity, the cohesive tractions are reduced to zero automatically and free crack surfaces are formed unless contact between the cracked surfaces re-establishes.

An infinitesimal change of the damage state at the interface as a result of an infinitesimal change of tractions requires the following equation to be satisfied so that the tractions, separations and damage parameter remain on the damage surface, i.e.

$$
d F=d f_{s}+d f_{g}=\sum_{i=1}^{2}\left(\frac{\partial f_{s}}{\partial \tilde{\tau}_{i}} d \tilde{\tau}_{i}+\frac{\partial f_{g}}{\partial G_{i}} d G_{i}\right)=0
$$

In general, damage growth is an irreversible non-linear process and an incremental formulation is required. The incremental form of the relationship between the interfacial cohesive tractions, separations and damage parameter can be obtained from Eq. (1) 


$$
d \tilde{\tau}_{i}=\sum_{j=1}^{2} \frac{\partial \tilde{\tau}_{i}}{\partial \delta_{j}} d \delta_{j}+\frac{\partial \tilde{\tau}_{i}}{\partial \omega} d \omega
$$

Substituting Eq. (10) into (9), making use of the following relationship which is obtained from Eq. (6)

$$
d G_{i}=\tilde{\tau}_{i} d \delta_{i}
$$

The incremental damage evolution law can be described in terms of incremental interfacial separations as

$$
d \omega=-\left(\sum_{i=1}^{2} \frac{\partial f_{g}}{\partial G_{i}} \tilde{\tau}_{i} d \delta_{i}+\sum_{i=1}^{2} \sum_{j=1}^{2} \frac{\partial f_{s}}{\partial \tilde{\tau}_{i}} \frac{\partial \tilde{\tau}_{i}}{\partial \delta_{j}} d \delta_{j}\right) / \sum_{i=1}^{2} \frac{\partial f_{s}}{\partial \tilde{\tau}_{i}} \frac{\partial \tilde{\tau}_{i}}{\partial \omega}
$$

Incremental interfacial constitutive law (combining cohesion and friction) is derived from equation (2) or (3)

$$
d \tau_{i}=\sum_{j=1}^{2} \frac{\partial \tau_{i}}{\partial \delta_{j}} d \delta_{j}+\frac{\partial \tau_{i}}{\partial \omega} d \omega
$$

The incremental constitutive relationship between the interfacial tractions and separations for the interface, which has taken account of the growth of damage, can then be obtained by substituting Eq. (12) into Eq. (13) to give

$$
d \tau_{i}=\sum_{j=1}^{2} \frac{\partial \tau_{i}}{\partial \delta_{j}} d \delta_{j}-\frac{\partial \tau_{i}}{\partial \omega}\left(\sum_{j=1}^{2} \frac{\partial f_{g}}{\partial G_{j}} \tilde{\tau}_{j} d \delta_{j}+\sum_{j=1}^{2} \sum_{l=1}^{2} \frac{\partial f_{s}}{\partial \tilde{\tau}_{j}} \frac{\partial \tilde{\tau}_{j}}{\partial \delta_{l}} d \delta_{l}\right) / \sum_{j=1}^{2} \frac{\partial f_{s}}{\partial \tilde{\tau}_{j}} \frac{\partial \tilde{\tau}_{j}}{\partial \omega}
$$

When the interfacial traction/stress state is either before damage initiation or under unloading conditions after damage has initiated, i.e. $F\left(\widetilde{\tau}_{i}, G_{i}\right)<0$, there will be no damage growth, thus

$$
d \omega=0
$$

and the incremental constitutive relationship becomes

$$
d \tau_{i}=\sum_{j=1}^{2} \frac{\partial \tau_{i}}{\partial \delta_{j}} d \delta_{j}
$$

The frictional sliding displacement $\delta_{s}$ is zero initially and is updated in the following incremental form when the interface is under through-thickness compression.

If $k_{2}\left|\delta_{2}-\delta_{s}\right|+\mu \tau_{1}<0$, then sticking takes place and 


$$
d \delta_{s}=0
$$

If $k_{2}\left|\delta_{2}-\delta_{s}\right|+\mu \tau_{1}>0$, then sliding takes place and

$$
d \delta_{s}=\left(\left|\delta_{2}-\delta_{s}\right|+\frac{\mu \tau_{1}}{k_{2}}\right) \cdot \frac{\delta_{2}-\delta_{s}}{\left|\delta_{2}-\delta_{s}\right|}
$$

The cohesive interface zone model developed above has been implemented into the commercial finite element code ABAQUS via a user subroutine, i.e. User Material for the Cohesive Element in ABAQUS.

\section{Behaviour of the Cohesive Interface under Through Thickness Compression}

The interface material properties for IM7/8552 UD ply in Table 1 were used to show the behaviour of the proposed cohesive zone model under through-thickness compression. Assuming a through-thickness compressive stress $\tau_{1}$ is applied and remains constant afterwards, the interface is then loaded by increasing the shear separation $\delta_{2}$ monotonically. Shear traction-separation relationships of the cohesive interface under different levels of through-thickness compressioin can be obtained by solving the equations in the previous section and are shown in Fig. 1. The classical bilinear behaviour is obtained for the cohesive traction-separation law when $\tau_{1}=0$ (and $\alpha=\beta=1$ was used in equation (7)). In general, there are four regions on each curve. The first is an initial linear part where traction increases in proportion to the separation, up to a point at which the elastic limit at $\tau_{2}=\tau_{2 \mathrm{c}}-\eta \tau_{1}$ is reached and damage initiation starts. In the second region, the traction continues to increase until reaching a peak value due to the gradual addition of the frictional stress, although cohesive shear stress decreases. The response in this region is however nonlinear. The third region is depicted by a continuous decrease in traction until full cohesive failure completes. After the formation of the crack, only the friction term with a constant value is left in the final region where post-damage friction takes place. Through-thickness compression increases the shear traction on the interface during the failure process, resulting in a higher traction at damage initiation and higher energy dissipation (area under the curve) as expected. The energy dissipated by the post-damage friction depends on the further crack propagation in the structure. A moderate through-thickness compressive stress will significantly enhance both the interfacial shear strength and fracture energy. 
Fig. 2 shows how the interfacial shear strength enhancement and friction affects the shear stress-sliding separation curve of the cohesive zone model under through-thickness compression. The following observations can be made by comparing the curves in Fig. 2 . Friction $(\eta=0.0, \mu=0.26)$ increases the shear stress on the interface and therefore the fracture energy, but has no effect on the resistance to damage initiation. The shear strength enhancement $(\eta=0.3, \mu=0.0)$ only retards damage initiation and has no effect on fracture energy. Combining shear strength enhancement and friction $(\eta=0.3, \mu=0.26)$ results in higher damage initiation stress and increased fracture energy for more fracture resistance.

\section{Simulating Shear Failure of Double-Notch Specimens}

Gan et al. [13] proposed a symmetric version of the double notch shear test and successfully measured interlaminar shear strength enhancement under increasing through-thickness compression. The specimens and the main features of the test are illustrated in Fig. 3. The specimens were made of unidirectional carbon epoxy pre-preg system IM7/8552. Two types of layup were used: $\left[(0 / 90)_{5} / 0_{3} /(90 / 0)_{5}\right]_{\mathrm{s}}$ for specimen $A$ and $\left[(0 / 90 / 0)_{4} / 0 /(0 / 90 / 0)_{4}\right]_{\mathrm{s}}$ for specimen $B$. Each ply is $0.125 \mathrm{~mm}$ thick. The depth of the notch equals quarter of the thickness of the specimen. During the test, to generate a through-thickness compression in the gauge section, a pair of compressive load $P$ was first applied via a pair of steel indenters. After the compression load was stabilised, the specimens were tested in tension by loading one end of the specimen longitudinally under displacement control mode while the other end was fixed. The final failure of the specimen was caused by the shear failure along the shear planes (indicated by the dotted lines in Fig. 3) in the gauge section under moderate throughthickness compression. Details of the experiments can be found in [13].

A two-dimensional FE analysis has been carried out to simulate the test of the above symmetric double notch specimen. The proposed cohesive zone model was used to model the interlaminar failure in the specimens. Due to symmetry, only half of the specimen was modelled. Since there is no constrain in the width direction of the specimen and material is brittle, the plies were modelled using four-node plane stress elements (CPS4 in ABAQUS). Cohesive elements were placed along the shear plane in the gauge section and along the interface at the same height as the shear plane shown in Fig.3 but outside the gauge section. Four-node two dimensional cohesive elements COH2D4 in ABAQUS were used. The steel indenter was modelled by $2 \mathrm{D}$ solid element with isotropic material properties of $E=210 \mathrm{GPa}$ and $v=0.3$. Frictionless contact between the steel indenter and the specimen was assumed. 
After mesh sensitivity study, an element size of $0.0625 \mathrm{~mm} \times 0.0625 \mathrm{~mm}$ was used for the $2 \mathrm{D}$ solid element for the plies and the cohesive element is $0.0625 \mathrm{~mm}$ long.

The ply material properties are given in Table 2 and the properties for the cohesive element are shown in Table 1. Schön [30] performed a reciprocating sliding test to measure the coefficient of friction (COF) of composite delamination surface from the same graphite fibre/epoxy matrix with slightly higher volume fraction of fibre. It was found that the COF for delamination surfaces between $0^{\circ} / 0^{\circ}$ decreased rapidly at first but then the decrease slowed down as the number of reciprocal sliding cycles increased. The maximum COF of $\mu=0.26$ measured at the first cycle was employed in the present simulation as this is the most appropriate $\mathrm{COF}$ for the delamination in the double-notch specimen tests conducted by Gan et al. [13].

Typical load-displacement curves from experiment, numerical prediction in [13] and the present simulation for specimens $A$ and $B$ are presented together in Fig. 4 and Fig. 5. The displacement measured in the experiment is the crosshead displacement which includes the deformation of the specimen as well as the compliance of the extension rods and the test machine [13]. To make the results more comparable, the predicted displacements from the numerical simulations were scaled to match the initial elastic slope of the experimental curves [13]. It can be seen that the predicted results are in good agreement with the experiments. Delamination initiates and propagates along the interface outside the gauge section at about $10 \mathrm{kN}$ longitudinal tensile load. These phenomena are captured by both the numerical simulation (indicated by the relatively big load plateaus on the curves) and the experiment (depicted by the small load plateaus/drops on the curves). It is also revealed by the numerical simulations that the final catastrophic failure occurs due to the shear failure in the gauge section in all cases. This is again in agreement with the experimental observation that there was no stable delamination propagation in the gauge section in the specimens during tests [13]. The present predictions also match the predicted results in [13] very closely, with the present model giving slightly higher final failure loads. The Bristol interface element model [27] used in [13] does not consider friction directly; instead, a single enhancement parameter is employed to relate the through-thickness compressive stress to the increase in interfacial shear strength and mode II fracture energy. The present cohesive zone model includes the enhanced interfacial shear strength, but considers the friction at micro/macro crack surfaces for increased fracture energy. On top of the enhanced interfacial shear strength, the inclusion of the friction at micro crack surfaces in the damage process zone in the present model further 
increases the maximum shear traction on the interface as shown in Fig. 2. The simulation shows that there is little full delamination in the entire gauge length before the catastrophic final failure of the specimen. This final failure is therefore a stress-based problem. This explains why the present model predicts slightly higher failure loads than the Bristol interface element model.

To describe the level of through-thickness compression, an average through-thickness compressive stress along the gauge length is determined from finite element analysis immediately after the through-thickness compression load is applied to the specimens for each case. The compression levels used in the experiment are given in Table 3 . The average shear strength of the specimen is also defined as the ratio between the longitudinal tensile load at final failure and the total shear failure area of the gauge section.

The comparisons between the predicted and experimental average shear strength of the specimen $A$ and $B$ are shown in Fig. 6 and Fig. 7, respectively, under different levels of through-thickness compression. It can be seen that there is a good agreement between the numerical and experimental results in all cases when enhancement $(\eta=0.3, \mu=0.26)$ is used. The numerical predictions are just $4 \% \sim 10 \%$ lower than the experimental average and close to the lower bound of experimental range.

Without shear strength enhancement $(\eta=0.0, \mu=0.26)$, the numerical prediction is reduced by $15 \%$ on average. Exclusion of friction in the model $(\eta=0.3, \mu=0.0)$ lowers the prediction by around $20 \%$ on average. If both are ignored $(\eta=0.0, \mu=0.0)$, the predictions are $39 \% \sim 56 \%$ lower than the experimental results for the cases simulated. This demonstrates that inclusion of both friction and the enhancement to the interfacial shear strength in the cohesive zone model is vital for an appropriate assessment of interfacial failure.

\section{Simulating Tensile Tests of Specimens with Cut and Dropped Plies}

The tensile tests conducted by Cui et al. [11] on specimens with cut and dropped plies have also been simulated using the proposed model. The specimens are illustrated in Fig. 8. There are two cases of cut-ply specimens (without a gap and with a $2 \mathrm{~mm}$ gap) and two cases of dropped-ply specimens with different taper angles (shallow angle of $5.7^{\circ}$ and sharp angle of $7.6^{\circ}$ ). The cut-ply specimens are made of two cut plies and eight continuous plies, and the dropped-ply specimens are made of two dropped plies and eight continuous plies. Each ply is 
$0.125 \mathrm{~mm}$ thick. Details of the specimens and experimental set-up and results can be found in [11].

Due to symmetry, only a quarter of the specimen was modelled. The specimen was meshed in the same manner as in the previous simulation of double-notch specimens. The plies were modelled using 2D solid element. The cohesive elements were placed along the interface between the cut/dropped plies and the continuous plies where the possible delamination would occur. An element size of $0.01 \mathrm{~mm}$ long and around $0.01 \mathrm{~mm}$ wide was used to mesh both cut/dropped and continuous plies. The cohesive element was $0.01 \mathrm{~mm}$ long. The tensile load was applied in a displacement controlled mode at the end of the specimen. For cut-ply specimen with gap and dropped-ply specimens, there are generally matrices inside the gap between the ends of the terminated plies. These matrices fractured earlier than the delamination initiation, thus the matrix regions have been ignored in the numerical models.

The specimens were made of unidirectional glass fibre-epoxy pre-preg (E-glass/913). The ply material properties are given in Table 4 and the properties for the cohesive element are shown in Table 5. Li et al. [27] carried out a sensitivity study on the selection of the interface stiffnesses $k_{1}$ and $k_{2}$ over a good range of values which showed little effect on the results. The $k_{1}$ and $k_{2}$ in Table 5 are well within this range.

$G_{I I C}$ and $\mu$ in Table 5 were obtained from other relevant sources. Wisnom and Jones [35] performed experiments to measure the coefficient of friction (COF) in mode II delamination with through-thickness compression for glass-fibre/epoxy composites and found that COF is 0.53. $G_{I I C}$ was extrapolated from the experimental results measured by Cui et al. [11] on the cut-ply and dropped-ply specimens as shown in Fig. 9. It should be pointed out that the average through-thickness stress was derived over the distance where the stress is compressive on the interface around the cut or drop end [11]. It is obvious that the compressive through thickness stress has a significant enhancing effect on the fracture energy. The least squares method was used to predict the trend of the best fit for experimental data. The quadratic curve fits the data perfectly for all four specimens. As the through-thickness stress is compressive, the fracture is in pure mode II. Once the through-thickness stress tends to infinitesimal or zero, its effect on mode II fracture energy diminishes and the quadratic trend curve gives a value of $G_{I I C}=1048 \mathrm{~J} / \mathrm{m}^{2}$.

The numerical simulation shows that damage initiates and develops at the tip of the cut or 
drop when the tensile load is increased to certain level, followed by a stable propagation of delamination for a few millimetres during which the load is continuously increasing. The delamination then propagates to the specimen end unstably, indicated by a drop (or plateau) on the nominal stress-strain curve shown in Fig. 10. This predicted phenomenon is consistent with the experimental observation described by Cui et al. [11].

The nominal stress in Fig.10 is defined as the ratio between the applied tensile load and the net sectional area at the mid of the specimen. Nominal strain is defined as the ratio between the applied tensile displacement and the length of quarter specimen. According to Cui et al. [11], the initial peak or the plateau on the nominal stress-strain curve is termed the delamination (propagation) stress.

Table 6 presents the delamination stress for all four types of specimen from experiments [11] and present predictions. The model taking account of the effect of compressive throughthickness stress $(\eta=0.18, \mu=0.53)$ produces predictions very close to the experimental results. $\eta=0.18$ was chosen from Xiao et al. [15] for E-Glass/Epoxy material. In fact, the shear strength enhancement factor $\eta$ has little effect on the predictions as indicated by the results from the model with $\eta=0.0$ and $\mu=0.53$. Numerical simulations have also been performed by assuming no enhancement at all $(\eta=0.0, \mu=0.0)$ in order to evaluate the effect of the friction on delamination stress. The inclusion of shear strength enhancement $(\eta=0.18, \mu=0.0)$ alone in the model does not enhance the delamination stress of these specimens. It is the friction which enhances the mode II fracture resistance of these specimens, especially in the case of specimen with dropped plies.

Fig. 11 shows the response of the interface at the position $(0.05 \mathrm{~mm}$ away from the ply drop tip) where the through-thickness compressive stress is the highest in the sharp dropped ply specimen. The shear stress has been separated into cohesive shear stress and frictional stress. As the specimen is loaded, the stresses at this point increase and damage initiates and develops. When the interface is fully cracked at this point (cohesive shear stress reduces to zero), delamination has propagated a distance of $a=0.05 \mathrm{~mm}$ from the drop ply end. Further loading of the specimen makes the delamination propagates further into the specimen. As the interface at this point is now fully delaminated, there is no cohesive shear stress, but there is still a frictional stress on the interface at this position. This frictional stress continues to dissipate energy as delamination propagates into the specimen. During the fracture process of the interface itself at this point, energy is absorbed by the decohesion of the interface and 
friction on the micro-crack surface consumes extra energy to increase fracture energy. However, post-delamination friction may also consume a significant amount of energy to further increase the fracture energy of the specimen. The larger the through-thickness compression zone is, the more energy will be consumed by post-delamination friction.

Stress distributions along the interface near the drop end in the sharp dropped ply specimen are shown in Fig. 12 at two stages: (1) when full delamination starts at the drop tip and (2) immediately before unstable delamination propagation. It can be seen that immediately before unstable delamination propagation in the specimen, there is a zone around $1.7 \mathrm{~mm}$ long where there is no cohesive shear stress caused by interface deformation. This indicates that this zone has been fully delaminated. This prediction is consistent with the experiment observation [11]. It is also shown that through-thickness compressive stress exists near the ply drop end. As delamination propagates, the compression zone extends and the intensity of the compressive stress at the drop end lowers slightly. More importantly, the high compressive through-thickness stress remains within a small region of less than $1 \mathrm{~mm}$ in length. When the delamination propagates to the interface $1 \mathrm{~mm}$ and further away from the ply drop end, the compressive through-thickness stress in the damaging zone ahead of the delamination tip is very low and will not enhance fracture resistance significantly. However, the postdelamination friction on the interface in the small region at the drop end may consume a significant amount of energy according to Fig. 11 and thus enhances the mode II fracture resistance of the tested and simulated specimens. Failure of the specimens with cut and dropped plies is caused by delamination propagation in the specimens, so it is a fracturemechanics-based problem which is fracture energy controlled. Adding the shear strength enhancement factor $\eta$ alone in the cohesive zone model only affects the damage initiation stress and does not increase fracture energy as shown in Fig. 2. This explains why the shear strength enhancement factor $\eta$ has little effect on the delamination stress for these specimens while friction does as shown in Table 6.

The catastrophic final failure of the double-notched specimen tests simulated in the previous section is a stress-based problem as already discussed. The test setup applied a quite uniformly distributed through-thickness compressive stress along the entire gauge length of the specimen. This increases both the interfacial shear strength and friction over the whole gauge section. Shear strength enhacement delays the damage initiation and friction during the damaging process of the interface also increases the shear stress to resist the deformation of the interface as indicated in Fig. 2. That is why the final failure loads of the double-notched 
specimens are sensitive to both shear strength enhacement factor $\eta$ and coefficient of friction $\mu$, as shown in Fig. 6 and 7.

\section{Conclusions}

A two-dimensional cohesive zone model has been developed to include the effect of compressive through-thickness stress on damage initiation and propagation. The novelties of the proposal are: (1) The new model accounts for both friction on micro/macro cracks and the enhancement of interfacial shear strength. (2) An independent shear strength enhancement factor $\eta$ is introduced, as there is no physical evidence that $\eta$ should be equal to the coefficient of friction $\mu$. These parameters should be measured by experimentation. (3) The model is formulated such that it would be straightforward to replace the present damage initiation criteria with another that considers the effect of through-thickness compressive stress. The proposed model has been validated against experimental data available in literature. The parametric study shows that the strategy adopted by other existing cohesive interface element models, to simply couple damage to friction, can already improve the prediction significantly. However, the enhancement of the interfacial shear strength also plays an important role in increasing fracture resistance, especially in the stress-based fracture problem, and must be included in the model as well to further improve the prediction.

Ideally, the measurement of $\eta$ requires a specimen and a loading which produce a uniform or almost uniform interlaminar shear stress and through-thickness compression over the entire failure interface so that it is a purely stress-based failure problem. Catastrophic failure occurs immediately after damage initiation on the interface. The experiment conducted by DeTeresa et al. [12] may be one of the candidates for this purpose.

\section{References}

[1] Dugdale DS. Yielding of steel sheets containing slits. Journal of the Mechanics and Physics of Solids 1960;8(2):100-104.

[2] Barenblatt GI. The mathematical theory of equilibrium cracks in brittle fracture. Advances in Applied Mechanics 1962;7:55-129.

[3] Tvergaard V. Effect of fibre debonding in a whisker-reinforced metal. Materials Science and Engineering 1990;A125(2):203-213.

[4] Xu Q, Tao W, Qu S, Yang Q. A cohesive zone model for the elevated temperature 
interfacial debonding and frictional sliding behaviour. Composites Science and Technology 2015;110:45-52.

[5] Alfano G, Crisfield MA. Finite element interface models for the delamination analysis of laminated composites: mechanical and computational issue. International Journal for Numerical Methods in Engineering 2001;50(7):1701-1736.

[6] Feng D, Aymerich F. Finite element modelling of damage induced by low-velocity impact on composite laminates. Composite Structures 2014;108:161-171.

[7] Yang QD, Thouless MD. Mixed-mode fracture analyses of plastically-deforming adhesive joints. International Journal of Fracture 2001;110(2):175-187.

[8] Jousset P, Rachik M. Comparison and evaluation of two types of cohesive zone models for the finite element analysis of fracture propagation in industrial bonded structures. Engineering Fracture Mechanics 2014;132:48-69.

[9] Yang QD, Cox B. Cohesive models for damage evolution in laminated composites. International Journal of Fracture 2005;133(2):107-137.

[10] Raous M. Interface models coupling adhesion and friction. Comptes Rendus Mecanique 2011;339(7):491-501.

[11] Cui W, Wisnom MR, Jones M. Effect of through-thickness tensile and compressive stresses on delamination propagation fracture energy. Journal of Composites Technology \& Research 1994;16(4):329-335.

[12] Deteresa SJ, Freeman DC, Groves SE. The effects of through-thickness compression on the interlaminar shear response of laminated fiber composites. Journal of Composite Materials 2004;38(8):681-697.

[13] Gan KW, Hallett SR, Wisnom MR. Measurement and modelling of interlaminar shear strength enhancement under moderate through-thickness compression. Composites Part A 2013;49:18-25.

[14] Yen CF, Caiazzo A. Innovative processing of multifunctional composite armor for ground vehicles. ARL-CR-484, US Army Research Laboratory, Aberdeen Proving Ground, MD, 2000.

[15] Xiao JR, Gillespie Jr JW. A phenomenological Mohr-Coulomb failure criterion for composite laminates under interlaminar shear and compression. Journal of Composite Materials 2007;41(11):1295-1309.

[16] Li DS, Wisnom MR. Modelling damage initiation and propagation in composites using interface elements. CADCOMP, Southampton, 1994;213-220.

[17] Fan C, Jar PYB, Cheng JJR. A unified approach to quantify the role of friction in beam-type specimens for the measurement of mode II delamination resistance of 
fibre-reinforced polymers. Composites Science and Technology 2007;67(6):989-995.

[18] Jia Y, Yan W, Liu HY. Carbon fibre pullout under the influence of residual thermal stresses in polymer matrix composites. Computational Materials Science 2012;62:7986.

[19] Sockalingam S, Dey M, Gillespie Jr JW, Keefe M. Finite element analysis of the microdroplet test method using cohesive zone model of the fiber/matrix interface. Composites Part A 2014;56:239-247.

[20] Chaboche JL, Girard R, Schaff A. Numerical analysis of composite systems by using interphase/interface models. Computational Mechanics 1997;20(1):3-11.

[21] Snozzi L, Molinari JF. A cohesive element model for mixed mode loading with frictional contact capability. International Journal for Numerical Methods in Engineering 2013;93(5):510-526.

[22] Oinonen A, Marquis G. A constitutive model for interface problems with frictional contact and cohesion. European Journal of Mechanics A/Solids 2015;49:205-213.

[23] Alfano G, Sacco E. Combining interface damage and friction in a cohesive-zone model. International Journal for Numerical Methods in Engineering 2006;68(5):542582.

[24] Serpieri R, Sacco E, Alfano G. A thermodynamically consistent derivation of a frictional-damage cohesive-zone model with different mode I and mode II fracture energies. European Journal of Mechanics A/Solids 2015;49:13-25.

[25] Serpieri R, Alfano G, Sacco E. A mixed-mode cohesive-zone model accounting for finite dilation and asperity degradation. International Journal of Solids and Structures 2015;67-68:102-115.

[26] Parrinello F, Failla B, Borino G. Cohesive-frictional interface constitutive model. International Journal of Solids and Structures 2009;46(13):2680-2692.

[27] Li X, Hallet SR, Wisnom MR. Predicting the effect of through-thickness compressive stress on delamination using interface elements. Composites Part A 2008;39(2):218230.

[28] Vandellos T, Huchette C, Carrère N. Proposition of a framework for the development of a cohesive zone model adapted to carbon-fiber reinforced plastic laminated composites. Composite Structures 2013;105:199-206.

[29] Guiamatsia I, Nguyen GD. A thermodynamics-based cohesive model for interface debonding and friction. International Journal of Solids and Structures 2014;51(34):647-659.

[30] Schön J. Coefficient of friction of composite delamination surfaces. Wear 
2000;237(1):77-89.

[31] Zou Z, Reid SR, Li S, Soden PD. A continuum damage model for delamination in laminated composites. Journal of the Mechanics and Physics of Solids 2003;51(2):333-356.

[32] Gutkin R, Pinho ST. Combining damage and friction to model compressive damage growth in fibre-reinforced composites. Journal of composite materials 2015;49(20):2483-2495.

[33] Hou JP, Petrinic N, Ruiz C. A delamination criterion for laminated composites under low-velocity impact. Composites Science and Technology 2001;61(14):2069-2074.

[34] Christensen RM, Deteresa SJ. Delamination failure investigation for out-of-plane loading in laminates. Journal of Composite Materials 2004;38(24):2231-2238.

[35] Wisnom MR, Jones MI. Measurement of friction in mode II delamination with through thickness compression. Proceedings of $7^{\text {th }}$ European conference on composite materials, ECCM7, London, 1996;87-92. 


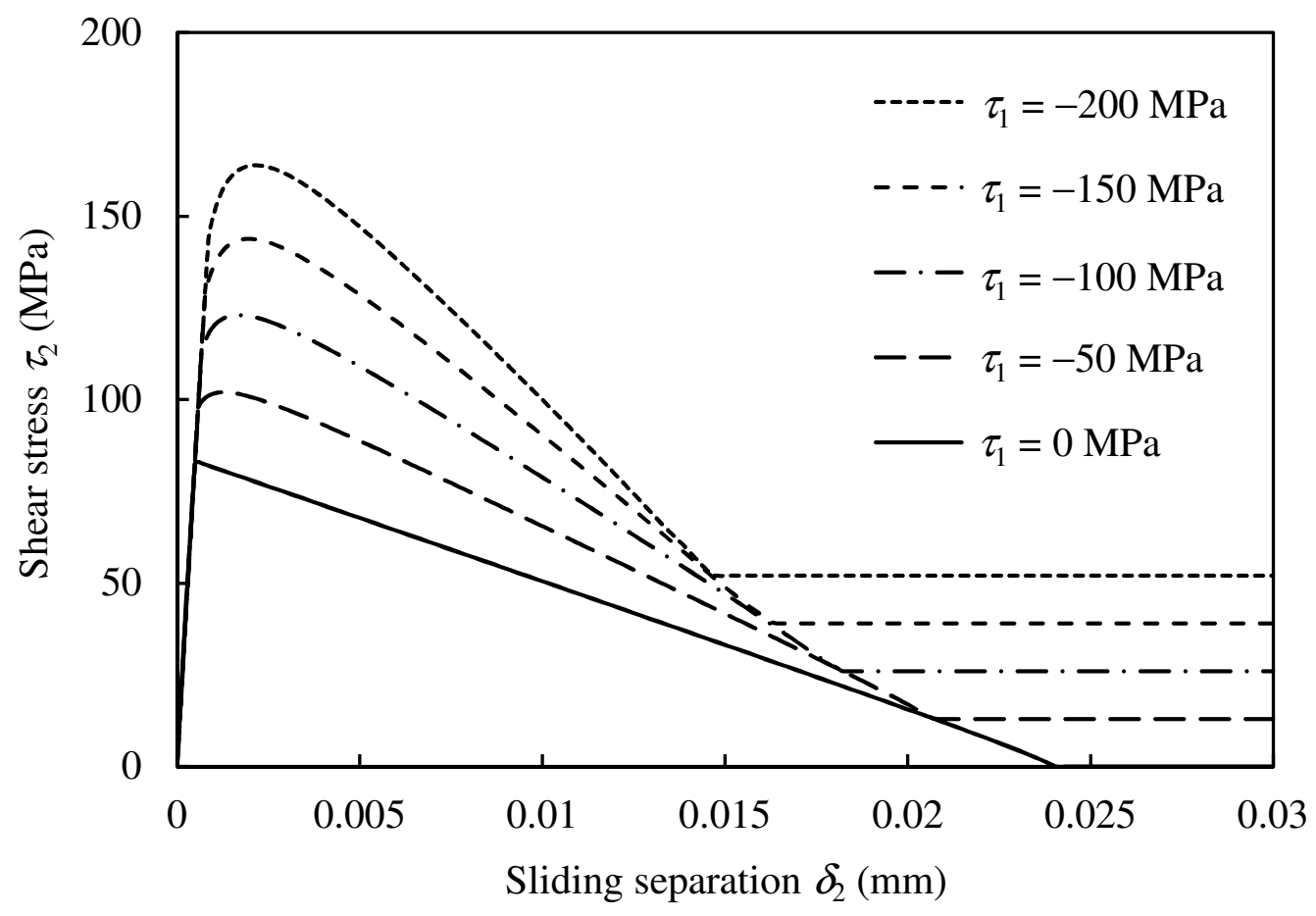

Figure 1 Effect of the through-thickness compression on the shear stress-sliding separation curves of the cohesive interface 


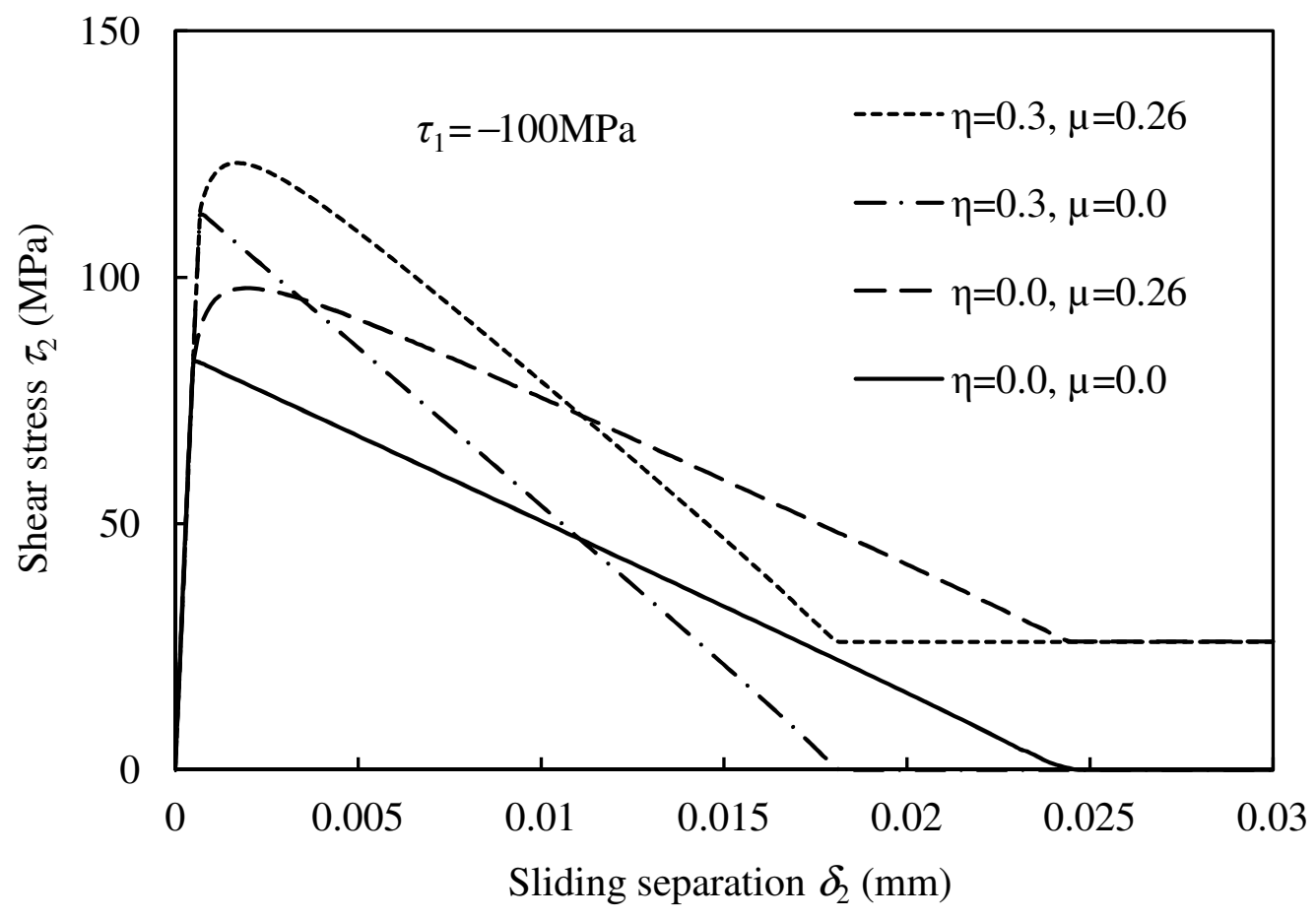

Figure 2 Effect of the shear strength enhancement and friction on the shear stress-sliding separation curves of the cohesive interface (through-thickness compressive stress $=100 \mathrm{MPa}$ ) 

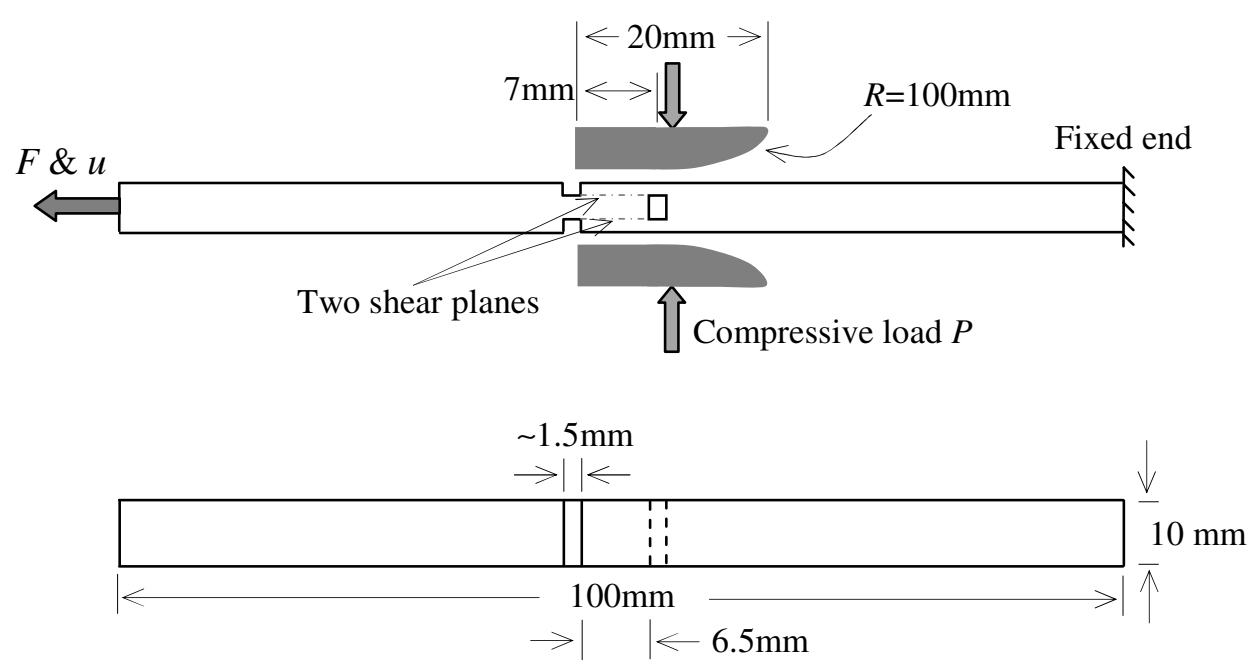

Figure 3 Schematic representation of the symmetric double-notch shear specimen (side and top view, only the untabbed section shown, not to scale) [13] 


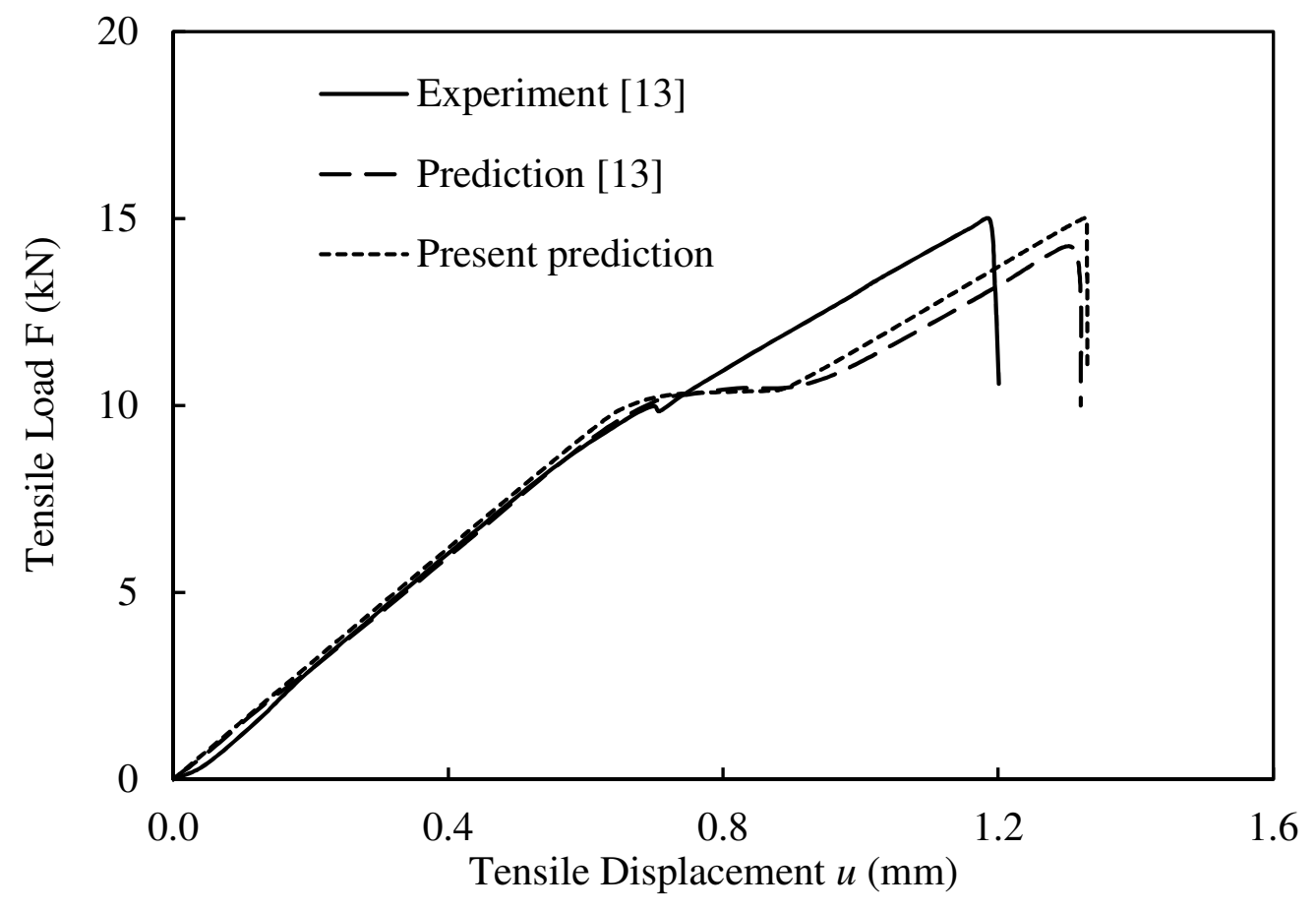

Figure 4 Tensile load-displacement curves for specimen $A$ at $P=10 \mathrm{kN}$ 


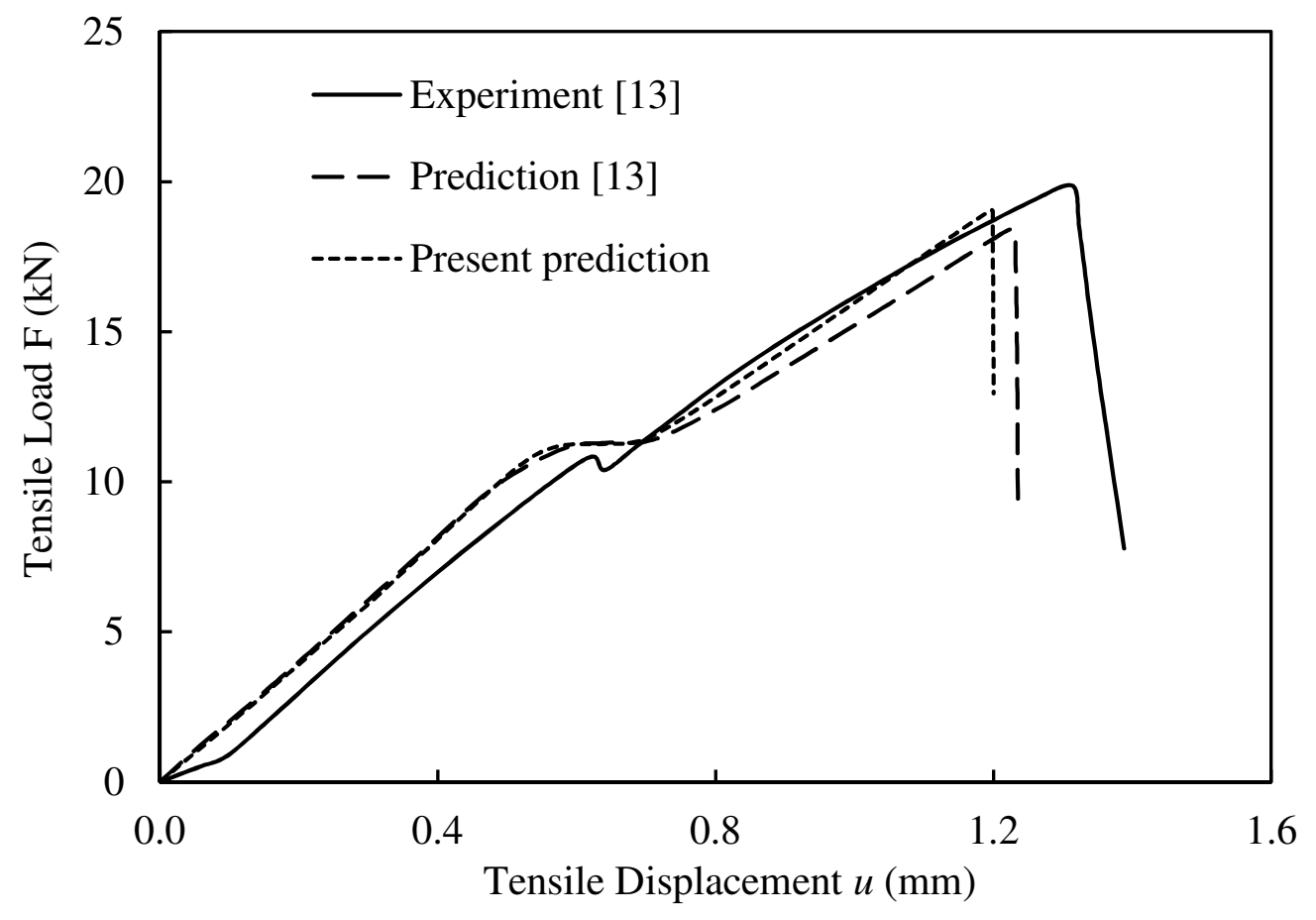

Figure 5 Tensile load-displacement curves for specimen $B$ at $P=20 \mathrm{kN}$ 


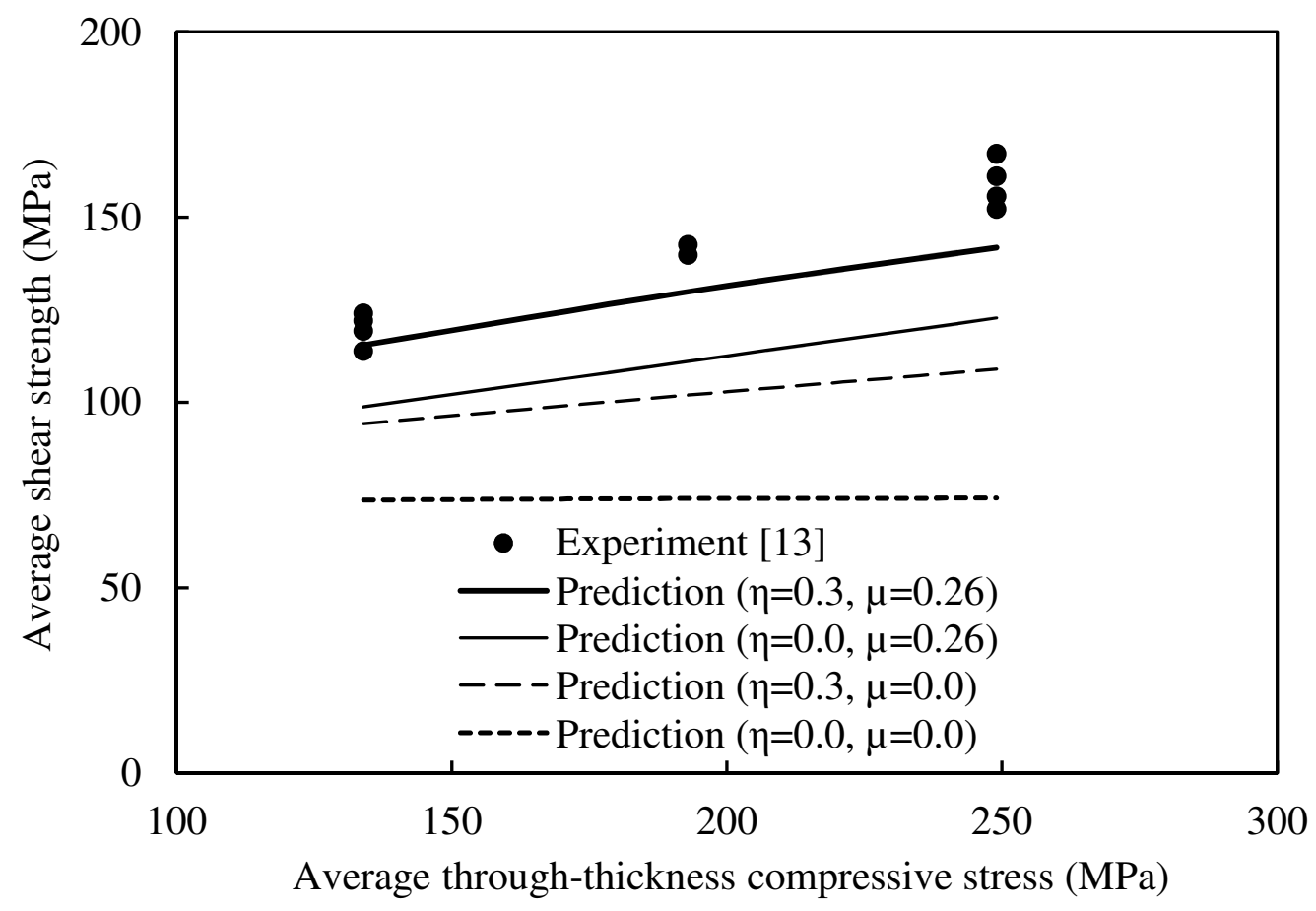

Figure 6 Experimental and FE predicted average interlaminar shear strength of specimen A under various through-thickness compression 


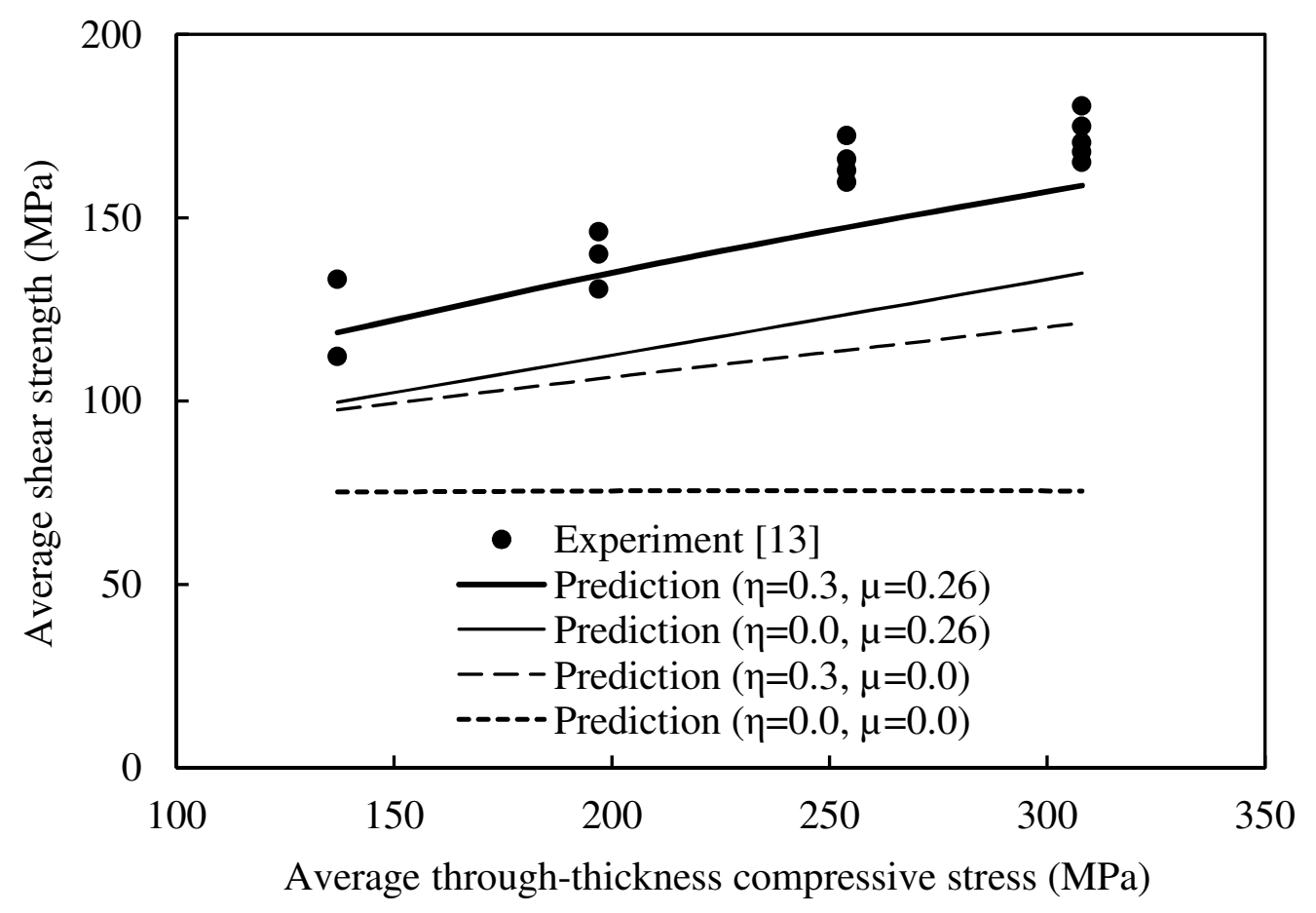

Figure 7 Experimental and FE predicted average interlaminar shear strength of specimen $B$ under various through-thickness compression 
(a)

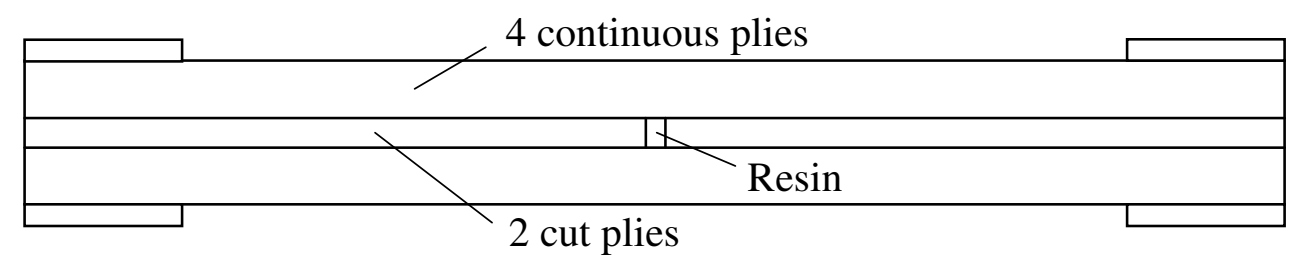

(b)

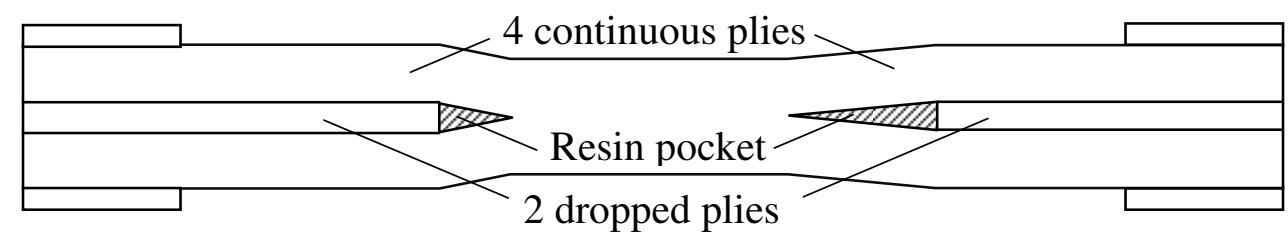

Figure 8 Schematic representation of (a) cut-ply and (b) dropped-ply specimens (not to scale) 


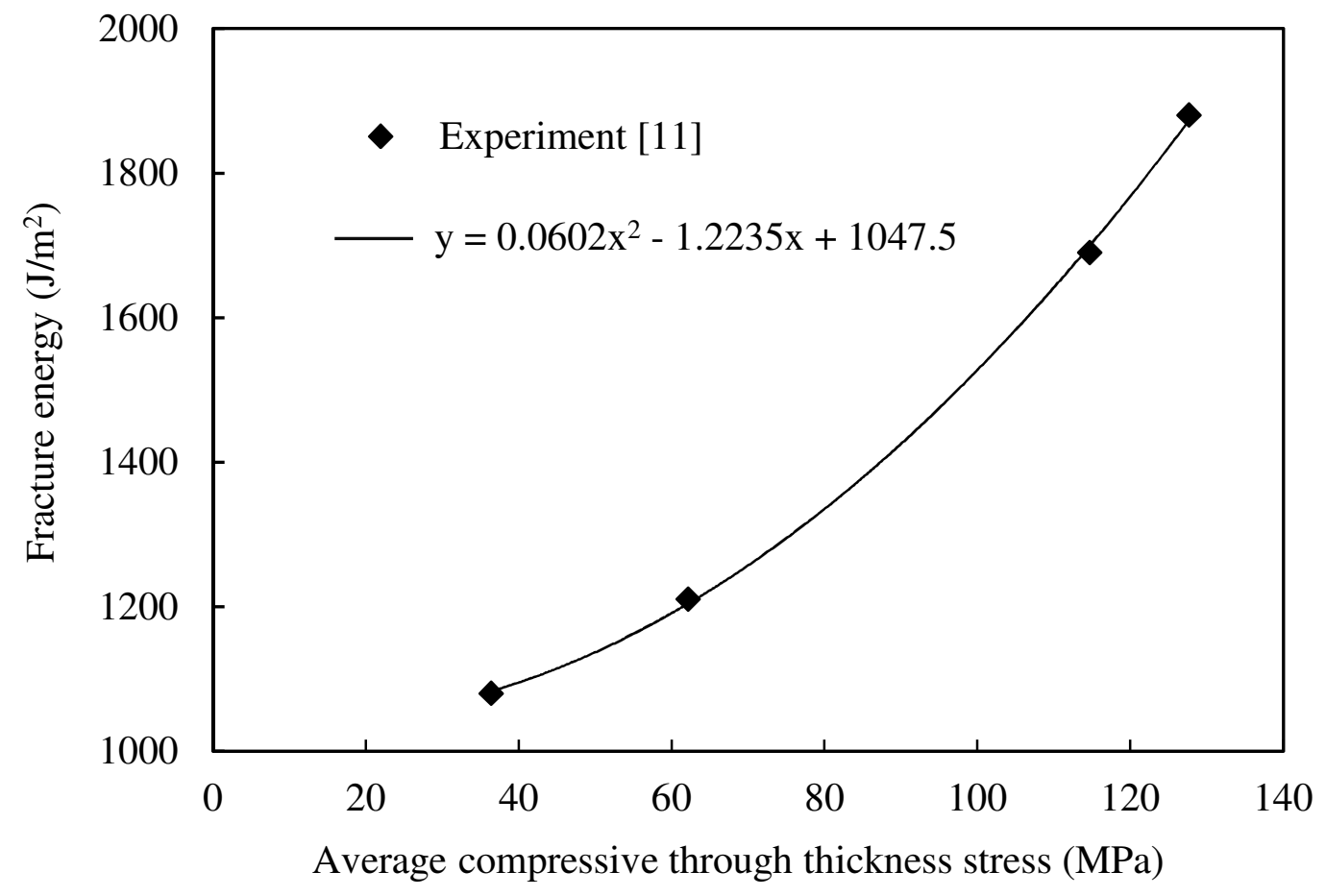

Figure 9 Effect of compressive through-thickness stress on fracture energy 


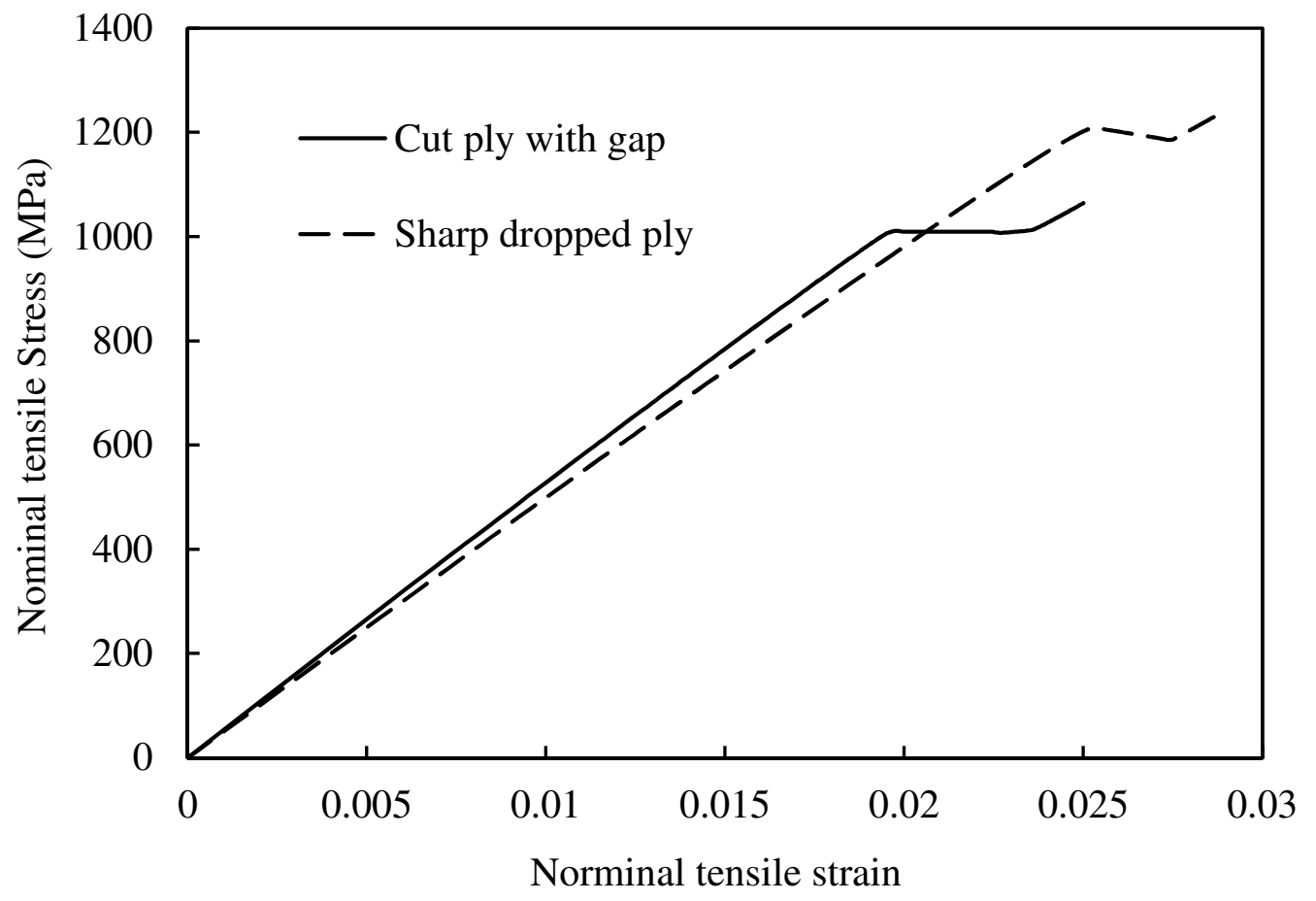

Figure 10 Predicted loading curves for cut ply and dropped ply specimens 


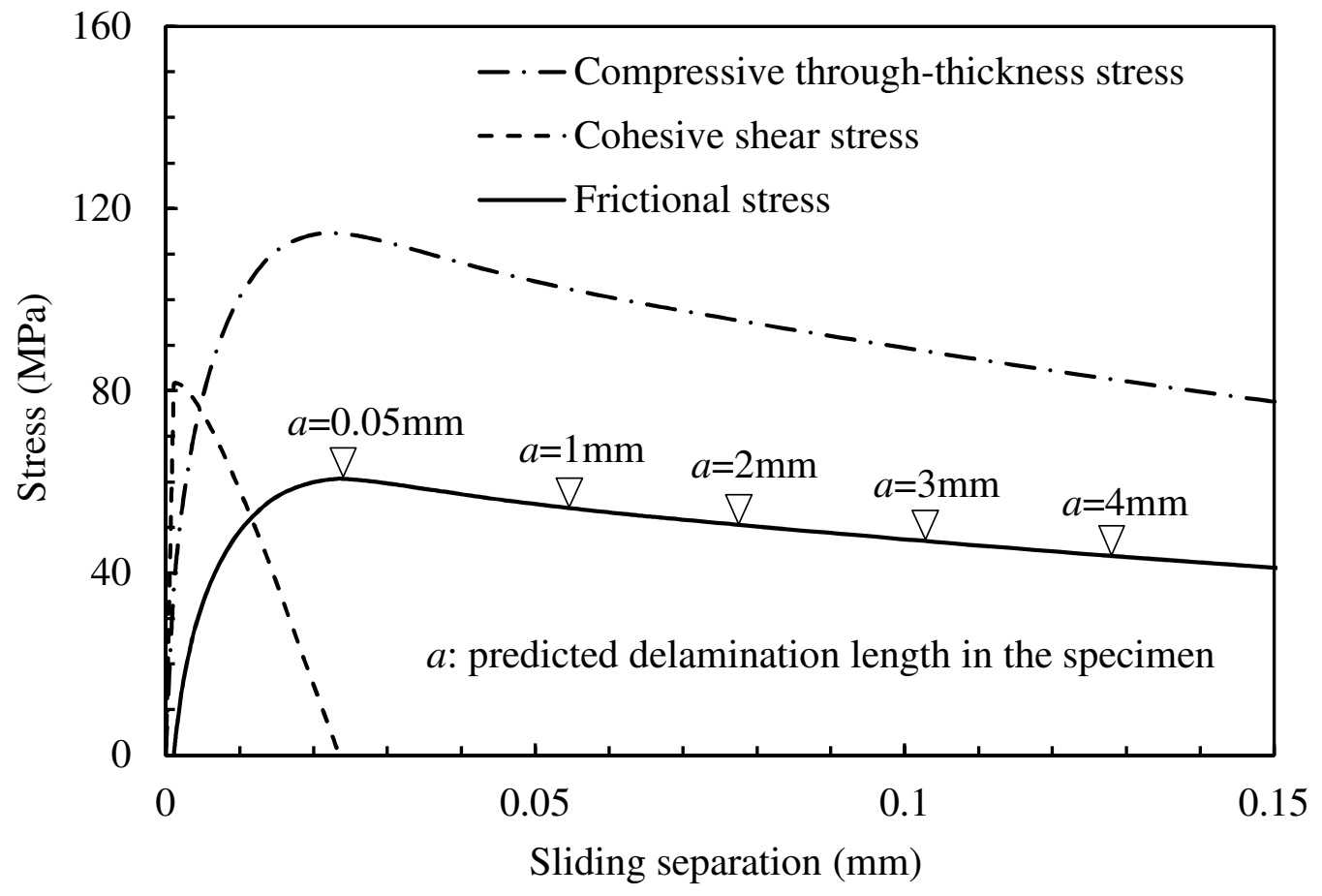

Figure 11 Response of the interface at the position $0.05 \mathrm{~mm}$ away from the ply drop end in the sharp dropped ply specimen ( $\nabla$ indicates that at this moment the delamination has propagated a distance $a$ from the drop end) 


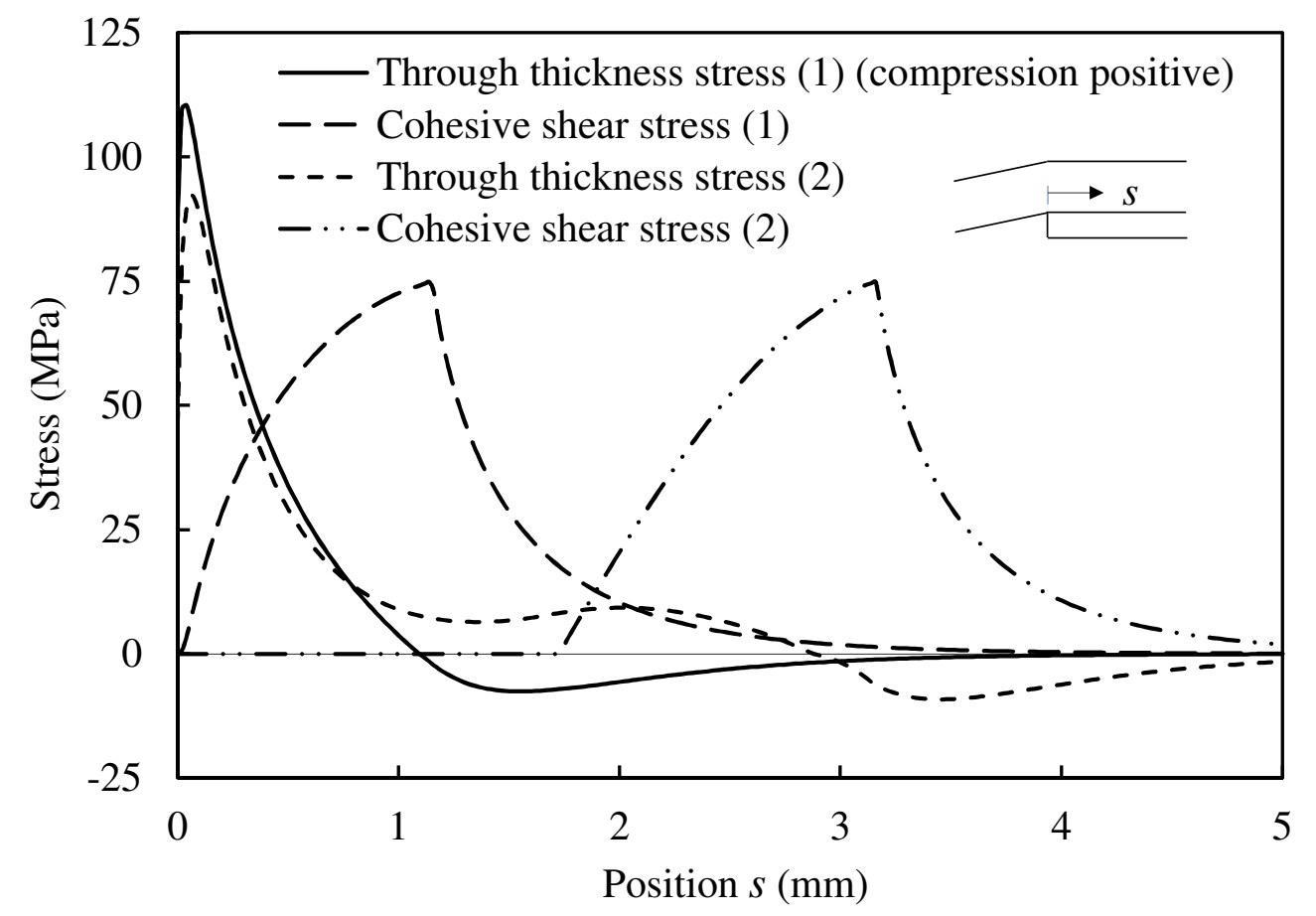

Figure 12 Traction distributions around the drop end in the sharp dropped ply specimen

(1) when full delamination starts at the drop end

(2) immediately before unstable delamination growth 
Table 1 Interface material properties for IM7/8552 UD ply [13]

\begin{tabular}{|c|c|c|c|c|c|c|c|}
\hline$\tau_{1 \mathrm{c}}(\mathrm{MPa})$ & $\tau_{2 \mathrm{c}}(\mathrm{MPa})$ & $k_{1}\left(\mathrm{~N} / \mathrm{m}^{3}\right)$ & $k_{2}\left(\mathrm{~N} / \mathrm{m}^{3}\right)$ & $G_{I C}\left(\mathrm{~J} / \mathrm{m}^{2}\right)$ & $G_{I I C}\left(\mathrm{~J} / \mathrm{m}^{2}\right)$ & $\eta$ & $\mu(*)$ \\
\hline 60 & 82.6 & $4.67 \times 10^{14}$ & $1.67 \times 10^{14}$ & 200 & 1000 & 0.3 & 0.26 \\
\hline
\end{tabular}

* Obtained from Schön [30]

Table 2 Material properties for IM7/8552 UD ply [13]

\begin{tabular}{|c|c|c|c|}
\hline$E_{1}(\mathrm{GPa})$ & $E_{2}(\mathrm{GPa})$ & $G_{12}(\mathrm{GPa})$ & $v_{12}$ \\
\hline 161 & 11.4 & 5.17 & 0.32 \\
\hline
\end{tabular}

Table 3 The compression levels used in the experiment

\begin{tabular}{|l|c|c|c|c|}
\hline Compression load $P(\mathrm{kN})$ & 10 & 15 & 20 & 25 \\
\hline Average $\tau_{1}$ in specimen $A(\mathrm{MPa})$ & -134 & -193 & -249 & -- \\
\hline Average $\tau_{1}$ in specimen $B(\mathrm{MPa})$ & -137 & -197 & -254 & -308 \\
\hline
\end{tabular}


Table 4 Material properties for E-glass/913 ply [27]

\begin{tabular}{|c|c|c|c|}
\hline$E_{1}(\mathrm{GPa})$ & $E_{2}(\mathrm{GPa})$ & $G_{12}(\mathrm{GPa})$ & $v_{12}$ \\
\hline 43.9 & 15.4 & 4.34 & 0.3 \\
\hline
\end{tabular}

Table 5 Interface material properties for E-glass/913 [27]

\begin{tabular}{|c|c|c|c|c|}
\hline$\tau_{1 \mathrm{c}}(\mathrm{MPa})$ & $\tau_{2 \mathrm{c}}(\mathrm{MPa})$ & $k_{1}, k_{2}\left(\mathrm{~N} / \mathrm{m}^{3}\right)$ & $G_{I I C}\left(\mathrm{~J} / \mathrm{m}^{2}\right)(*)$ & $\mu(*)$ \\
\hline 94 & 75 & $10^{14}$ & 1048 & 0.53 \\
\hline
\end{tabular}

* Obtained from other sources

Table 6 Comparison between experimental and predicted delamination stress (MPa)

\begin{tabular}{|l|c|c|c|c|}
\hline & $\begin{array}{c}\text { Cut ply } \\
\text { (no gap) }\end{array}$ & $\begin{array}{c}\text { Cut ply } \\
\text { (with gap) }\end{array}$ & $\begin{array}{c}\text { Dropped ply } \\
\text { (shallow) }\end{array}$ & $\begin{array}{c}\text { Dropped ply } \\
\text { (sharp) }\end{array}$ \\
\hline Experiment [11] & 966 & 1021 & 1208 & 1274 \\
\hline $\begin{array}{l}\text { Present model } \\
\eta=0.18, \mu=0.53\end{array}$ & $1009(4.5 \%)$ & $1011(-1.0 \%)$ & $1180(-2.3 \%)$ & $1209(-5.1 \%)$ \\
\hline $\begin{array}{l}\text { Present model } \\
\eta=0.0, \quad \mu=0.53\end{array}$ & $1009(4.5 \%)$ & $1012(-0.9 \%)$ & $1180(-2.3 \%)$ & $1208(-5.2 \%)$ \\
\hline $\begin{array}{l}\text { Present model } \\
\eta=0.0, \mu=0.0\end{array}$ & $949(-1.8 \%)$ & $954(-6.6 \%)$ & $948(-21.5 \%)$ & $948(-25.6 \%)$ \\
\hline $\begin{array}{l}\text { Present model } \\
\eta=0.18, \mu=0.0\end{array}$ & $949(-1.8 \%)$ & $954(-6.6 \%)$ & $948(-21.5 \%)$ & $948(-25.6 \%)$ \\
\hline
\end{tabular}

* Values in bracket are relative difference to the experimental results. 